\title{
Backbone and Ile, Leu, Val methyl group resonance assignment of CoV-Y domain of SARS-CoV-2 non-structural protein 3
}

\author{
Yulia Pustovalova ${ }^{1}\left[\right.$. Oksana Gorbatyuk ${ }^{1} \cdot$ Yunfeng $\mathrm{Li}^{1} \cdot$ Bing Hao $^{1} \cdot$ Jeffrey C. Hoch ${ }^{1}$
}

Received: 15 September 2021 / Accepted: 12 November 2021 / Published online: 18 November 2021

(C) The Author(s), under exclusive licence to Springer Nature B.V. 2021

\begin{abstract}
The worldwide COVID-19 pandemic is caused by severe acute respiratory syndrome coronavirus 2 (SARS-CoV-2). Nonstructural protein 3 (nsp3) has 1945 residues and is the largest protein encoded by SARS-CoV-2. It comprises more than a dozen independent domains with various functions. Many of these domains were studied in the closely-related virus SARS$\mathrm{CoV}$ following an earlier outbreak. Nonetheless structural and functional information on the C-terminal region of nsp3 containing two transmembrane and three extra-membrane domains remains incomplete. This part of the protein appears to be involved in initiation of double membrane vesicle (DMV) formation, membranous organelles the virus builds to hide its replication-transcription complex from host immune defenses. Here we present the near-complete backbone and Ile, Leu, and Val methyl group chemical shift assignments of the most C-terminal domain of nsp3, CoV-Y. As the exact function and binding partners of CoV-Y remain unknown, our data provide a basis for future NMR studies of protein-protein interactions to elucidate the molecular mechanism of DMV formation.
\end{abstract}

Keywords SARS-CoV-2 $\cdot \mathrm{CoV}-\mathrm{Y}$ domain $\cdot \mathrm{nsp} 3 \cdot$ Methyl assignment

\section{Biological context}

The severe acute respiratory syndrome coronavirus 2 (SARS-CoV-2) has been responsible for the current worldwide COVID-19 pandemic since 2019. Following the outbreaks of SARS-CoV in 2002-2003 and the Middle East respiratory syndrome (MERS-CoV) in 2012 this is the third instance of a global coronavirus outbreak.

Like other (+) RNA viruses SARS-CoV-2 forms specialized, membranous organelles in infected cells. These double membrane vesicles (DMVs) create a favorable microenvironment for the viral replication-transcription complex by concentrating viral components and at the same time shielding them from the host immune defense (Shulla and Randall 2016). All SARS-CoV, SARS-CoV-2 and

Yulia Pustovalova

ypustovalova@uchc.edu

$\triangle$ Jeffrey C. Hoch

hoch@uchc.edu

1 Department of Molecular Biology and Biophysics, University of Connecticut Health Center, Farmington, CT 06030, USA
MERS-CoV specifically target the Endoplasmic Reticulum (ER) membrane and rearrange it into interconnected spherical 200-300 nm DMVs (Wolff et al. 2020). It was shown that SARS-CoV non-structural protein 3 (nsp3) together with nsp4 and nsp6 plays a key role in DMV formation (Angelini et al. 2013; Hagemeijer et al. 2014). In a hexameric form, $\mathrm{nsp} 3$ forms a molecular pore that connects the DMV interior with the cytosol (Wolff et al. 2020). Nsp3 of SARS-CoV and SARS-CoV-2 have $75.8 \%$ sequence identity and share the same domain organization. This $222 \mathrm{kDa}$ protein consists of more than a dozen domains that can be roughly divided in two parts. The first, nsp3N, consists of ten N-terminal cytosolic domains with different functions including a papain-like protease (Lei et al. 2018) and a scaffold region that participates in the replication-transcription complex assembly (Imbert et al. 2008). The second, nsp3C, has two transmembrane domains (TM1 and TM2) with a luminal loop (Ecto3) between them and two cytosolic domains (Y1 and CoV-Y) following TM2. Nsp3C anchors nsp3 to the ER membrane and induces membrane rearrangement (Angelini et al. 2013; Hagemeijer et al. 2014). However, the molecular mechanism of nsp3C-induced DMV formation remains 


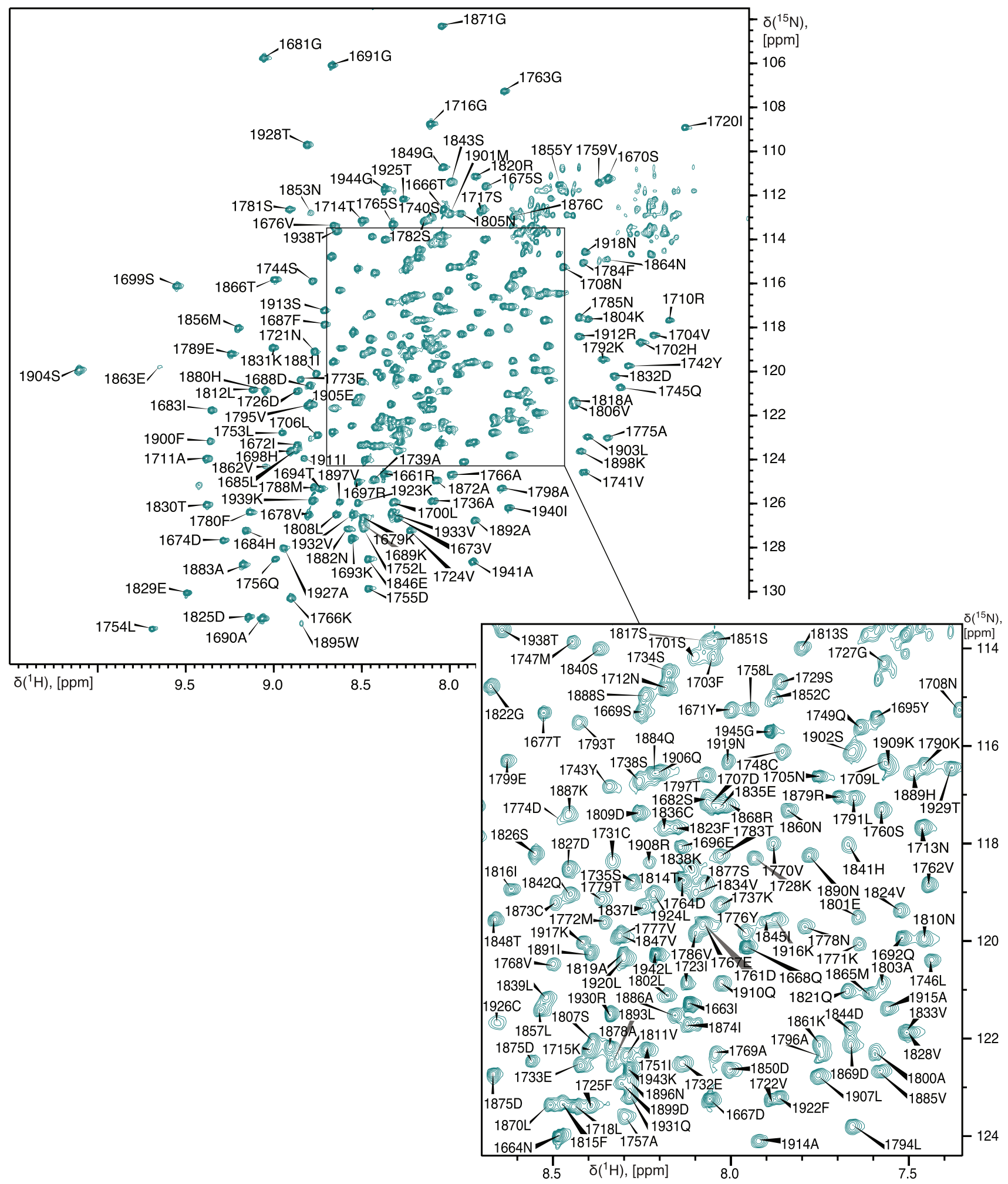

Fig. 1 Assigned ${ }^{1} \mathrm{H}_{-}{ }^{15} \mathrm{~N}$ TROSY-HSQC spectrum of partially deuterated U- $\left[{ }^{15} \mathrm{~N}-{ }^{13} \mathrm{C}\right]-\mathrm{nsp} 3 \mathrm{CoV}-\mathrm{Y}$ domain at $0.35 \mathrm{mM}$ concentration in $20 \mathrm{mM}$ MOPS buffer pH 6.4, $100 \mathrm{mM} \mathrm{LiBr}, 2 \mathrm{mM}$ DTT, $0.01 \%$
$\mathrm{NaN}_{3}$ and $10 \% \mathrm{D}_{2} \mathrm{O}$ measured at $25^{\circ} \mathrm{C}$ on a Varian Inova $800 \mathrm{MHz}$ NMR spectrometer. The inset shows an expansion of the central region of the spectrum 


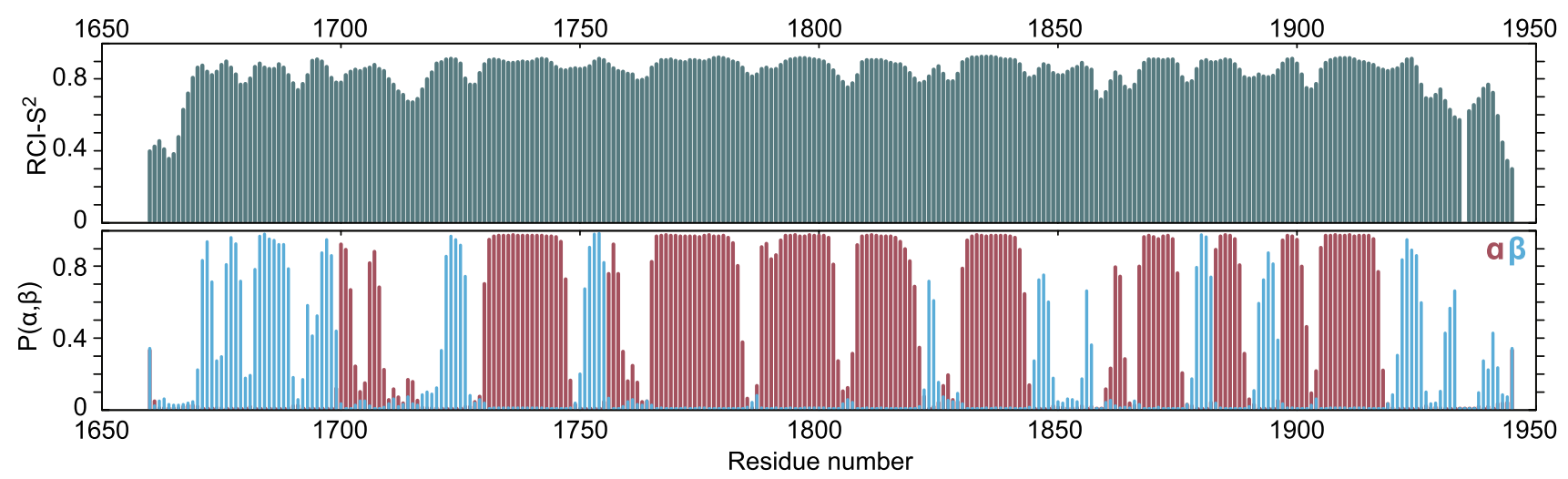

Fig. 2 Results from Talos +. The top panel shows predicted random-coil-index-derived order parameters $\mathrm{S}^{2}$. The bottom panel shows the probability of each residue adopting a secondary structure (burgundy $-\alpha$-helix, light blue $-\beta$-strand)

unknown because of a lack of structural information for nsp3C domains.

The focus of this work is CoV-Y, the most C-terminal domain of SARS-CoV-2 nsp3. This domain is present in all coronaviruses. The level of its conservation is close to that for the enzymatic domains of nsp3 and exceeds nonenzymatic ones (Neuman 2016). However, the function of the nsp3 CoV-Y domain is unknown. Here, we present the resonance assignments of the backbone ${ }^{1} \mathrm{H}^{\mathrm{N}},{ }^{15} \mathrm{~N},{ }^{13} \mathrm{C},{ }^{13} \mathrm{C} \alpha$, ${ }^{13} \mathrm{C} \beta$ and methyl ${ }^{1} \mathrm{H}$ and ${ }^{13} \mathrm{C}$ (Ile, Leu, Val) nuclei of SARSCoV-2 nsp3 CoV-Y domain. These assignments will facilitate investigation of nsp3 CoV-Y function and interactions with other SARS-CoV-2 proteins.

\section{Methods and experiments}

\section{Construct design}

We previously described expression and purification of nsp3 CoV-Y (residues 1638-1945) (Altincekic et al. 2021). This construct provided good quality ${ }^{1} \mathrm{H}^{-}{ }^{15} \mathrm{~N}$ TROSY-HSQC spectra but a long $\mathrm{N}$-terminal unstructured region (approximately 30 residues) complicated the assignment. In this work we used a shorter construct of nsp3 CoV-Y that corresponds to residues $1660-1945$ based on the NCBI reference sequence YP_009742610.1. The gene sequence was $E$. coli codon optimized and cloned into a pET28b $(+)$ vector containing a removable tobacco etch virus (TEV) protease recognition site. After TEV cleavage, the final construct contained an artificial $\mathrm{N}$-terminal glycine residue preceding the native $\mathrm{CoV}-\mathrm{Y}$ sequence.

\section{Sample preparation}

For backbone assignment we produced partially deuterated $\mathrm{U}-\left[{ }^{15} \mathrm{~N}-{ }^{13} \mathrm{C}\right]-\mathrm{nsp} 3 \mathrm{CoV}-\mathrm{Y}$ protein by growing BL21
(DE3) E. coli cells transformed with the pET28b(+) plasmid encoding CoV-Y domain in $\mathrm{M} 9$ media using $\mathrm{D}_{2} \mathrm{O}$ with $1 \mathrm{mg} / \mathrm{L} \mathrm{U}-\left[{ }^{15} \mathrm{~N}\right]$-labeled ammonium chloride and $4 \mathrm{mg} / \mathrm{L}$ $\mathrm{U}-\left[{ }^{13} \mathrm{C}\right]$-labeled D-glucose as sole sources of nitrogen and carbon, respectively.

For methyl labeling of the nsp3 CoV-Y domain we used the procedure described by Tugarinov et al. (Tugarinov and Kay 2004; Tugarinov et al. 2005). A U- $\left[{ }^{15} \mathrm{~N},{ }^{13} \mathrm{C},{ }^{2} \mathrm{H}\right]$, Ile $\delta_{1}$ $\left[{ }^{13} \mathrm{CH}_{3}\right]$, Leu, Val- $\left[{ }^{13} \mathrm{CH}_{3},{ }^{12} \mathrm{CD}_{3}\right]$-labeled sample of nsp3 CoV-Y (U- $\left.\left[{ }^{15} \mathrm{~N},{ }^{13} \mathrm{C},{ }^{2} \mathrm{H}\right]-\mathrm{ILV}\right)$ was produced using $\mathrm{D}_{2} \mathrm{O}$ M9 media with $1 \mathrm{mg} / \mathrm{L} \mathrm{U}-\left[{ }^{15} \mathrm{~N}\right]$-labeled ammonium chloride and $4 \mathrm{mg} / \mathrm{L} \mathrm{U}-\left[{ }^{13} \mathrm{C},{ }^{2} \mathrm{H}\right]$-labeled D-glucose. For selective methyl protonation $70 \mathrm{mg} / \mathrm{L}$ of $\left[{ }^{13} \mathrm{C}_{4} ; 3,3-{ }^{2} \mathrm{H}_{2}\right]$-alpha-ketobuterate and $140 \mathrm{mg} / \mathrm{L}$ of $\left[1,2,3,4-{ }^{13} \mathrm{C}_{4} ; 3,4^{\prime}, 4^{\prime}, 4^{\prime}-{ }^{2} \mathrm{H}_{4}\right]$-alpha-ketoisovaleriate were added 1 hour prior to induction. All isotopes were purchased from Cambridge Isotope Laboratories, Inc.

The protein was purified as described previously (Altincekic et al. 2021) with two modifications: (I) we added $1 \mathrm{mM}$ of tris (2-carboxyethyl) phosphine (TCEP) after TEVcleavage of the $\mathrm{His}_{6}$-tag to reduce cysteine side chains; (II) we changed the final buffer because the computed $\mathrm{pI}$ was reduced from 7.1 to 6.6 for the new shorter construct. All NMR samples were prepared in $20 \mathrm{mM}$ MOPS buffer $\mathrm{pH}$ 6.4, $100 \mathrm{mM} \mathrm{LiBr}, 2 \mathrm{mM}$ DTT and $0.01 \% \mathrm{NaN}_{3}$.

\section{NMR experiments}

All NMR experiments were recorded at $25{ }^{\circ} \mathrm{C}$ on a Varian Inova $800 \mathrm{MHz}$ spectrometer equipped with a cryogenic triple-resonance probe. For the backbone resonance assignments a sample of $0.35 \mathrm{mM}$ partially deuterated $\mathrm{U}-\left[{ }^{15} \mathrm{~N}-{ }^{13} \mathrm{C}\right]-\mathrm{nsp} 3 \mathrm{CoV}-\mathrm{Y}$ in NMR buffer with $10 \% \mathrm{D}_{2} \mathrm{O}$ was used. A set of NMR experiments for backbone ${ }^{15} \mathrm{~N}$, ${ }^{13} \mathrm{C}$ and ${ }^{1} \mathrm{H}$ resonance assignment consisted of $2 \mathrm{D}{ }^{1} \mathrm{H}$ ${ }^{15} \mathrm{~N}$ TROSY-HSQC and three-dimensional non-uniformly 


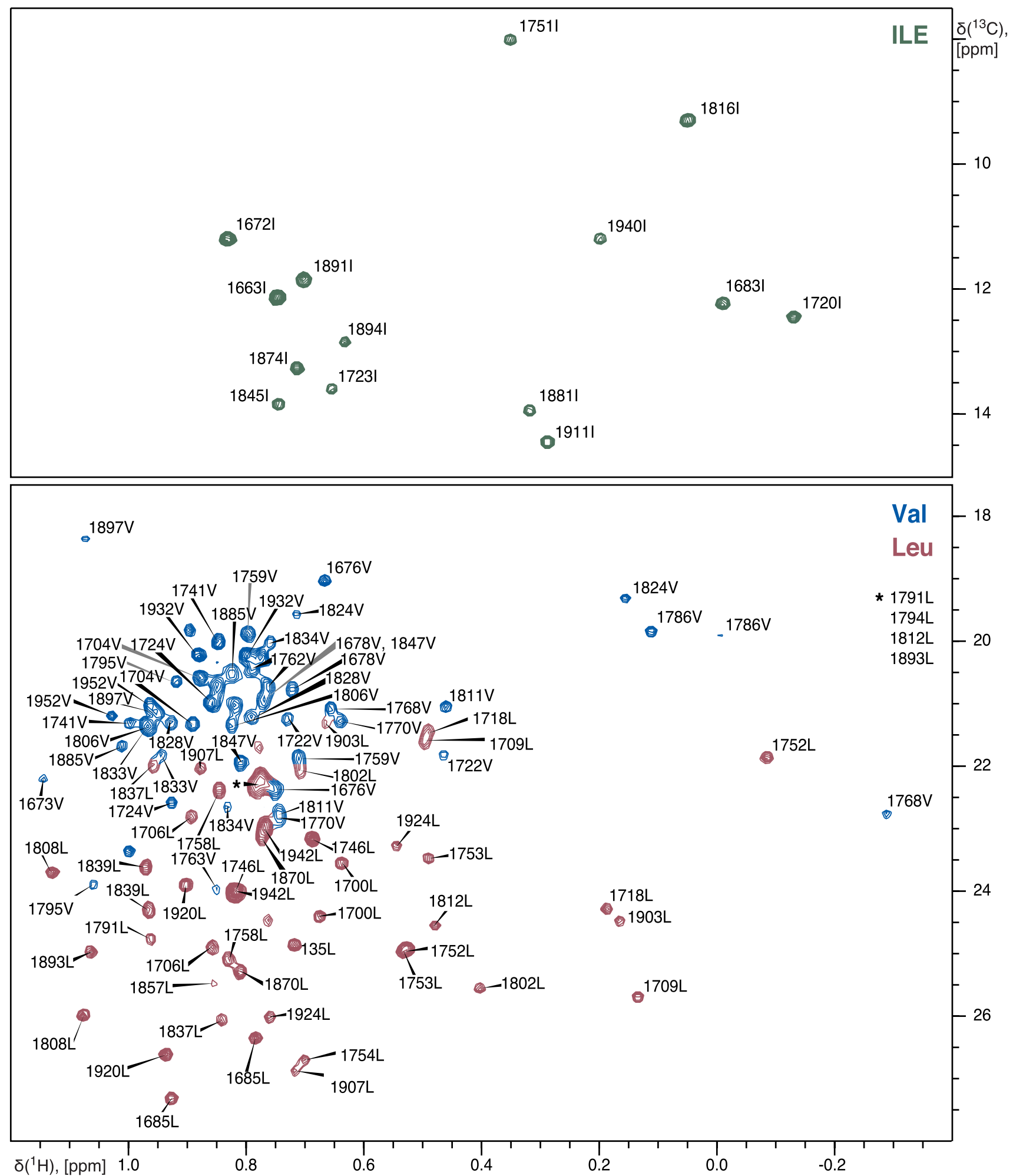

Fig. 3 Assigned ${ }^{1} \mathrm{H}^{-13} \mathrm{C}$ HSQC spectrum of $\mathrm{U}_{-}\left[{ }^{15} \mathrm{~N},{ }^{13} \mathrm{C},{ }^{2} \mathrm{H}\right]$, Ile $\delta_{1^{-}}$$\left[{ }^{13} \mathrm{CH}_{3}\right]$, Leu,Val- $\left[{ }^{13} \mathrm{CH}_{3},{ }^{12} \mathrm{CD}_{3}\right]$-labeled nsp3 CoV-Y domain at $0.25 \mathrm{mM}$ concentration in $20 \mathrm{mM}$ MOPS buffer pH 6.4, $100 \mathrm{mM}$ $\mathrm{LiBr}, 2 \mathrm{mM}$ DTT, $0.01 \% \mathrm{NaN}_{3}$ and $10 \% \mathrm{D}_{2} \mathrm{O}$ measured at $25^{\circ} \mathrm{C}$ on a
Varian Inova $800 \mathrm{MHz}$ NMR spectrometer. For clarity methyl groups are shown with different colors: Ile $\delta_{1}$, dark green; Leu $\delta_{1,2}$, dark red; Val $\gamma_{1,2}$, blue 
sampled TROSY-based HNCO (15\%), HNCACO (15\%), HNCA (16\%), HNCACB (14\%) (Yang and Kay 1999) and ${ }^{15} \mathrm{~N}$-edited NOESY-HSQC (20\%) with $140 \mathrm{~ms}$ mixing time (Zhang et al. 1994). For the assignment of Ile $\delta_{1}$, Leu $\delta_{1,2}$ and Val $\gamma_{1,2}$ methyl groups a $0.25 \mathrm{mM} \mathrm{U}-\left[{ }^{15} \mathrm{~N},{ }^{13} \mathrm{C},{ }^{2} \mathrm{H}\right]-\mathrm{ILV}$ sample was used. We recorded $2 \mathrm{D}{ }^{1} \mathrm{H}^{-13} \mathrm{C} \mathrm{HSQC}$ and 3D HMCMCGCBCA (Tugarinov and Kay 2003) acquired with $20 \%$ NUS sampling coverage.

All spectra were processed using NMRpipe (Delaglio et al. 1995) and SMILE for NUS spectral reconstruction (Ying et al. 2017).

\section{Assignment and data deposition}

Analysis of the spectra and backbone resonance assignment were performed manually using CARA (Keller 2004). The ${ }^{1} \mathrm{H}_{-}{ }^{15} \mathrm{~N}$ TROSY-HSQC spectrum of nsp3 CoV-Y domain shows excellent signal dispersion for a 286-residue protein (Fig. 1). Backbone assignment is nearly complete $\left(97 \% \mathrm{H}^{\mathrm{N}}\right.$, 94\% N, 98\% $\left.\mathrm{C}^{\prime}, 98 \% \mathrm{C} \alpha, 90 \% \mathrm{C} \beta\right)$. There are nine missing residue assignments, K1660, N1680, N1854, T1858, Y1859, N1934-T1937 in the ${ }^{1} \mathrm{H}_{-}{ }^{15} \mathrm{~N}$ TROSY-HSQC spectrum. The $\mathrm{HN}$ peaks for missing residues are probably broadened beyond detection in the ${ }^{1} \mathrm{H}_{-}{ }^{15} \mathrm{~N}$ TROSY-HSQC. A few unassigned low intensity peaks in ${ }^{1} \mathrm{H}_{-}{ }^{15} \mathrm{~N}$ TROSY-HSQC spectrum don't provide identifiable cross-peaks in $3 \mathrm{D}$ spectra for reliable correlation.

Measured backbone chemical shifts were used as input for Talos + (Shen and Bax 2015) to calculate the randomcoil-index-derived order parameters (RCI-S ${ }^{2}$ ) and secondary structure propensities (Fig. 2). Our results suggest that the CoV-Y domain possesses a well-ordered globular $\alpha / \beta$ fold with flexible termini (eight $\mathrm{N}$-terminal residues and four C-terminal residues). These terminal residues as well as residues 1932-1936 have RCI-S ${ }^{2}<0.65$ (Fig. 2). This probably explains why peaks corresponding to N1934-T1937 are broadened beyond detection in the ${ }^{1} \mathrm{H}-$

${ }^{15} \mathrm{~N}$ TROSY-HSQC spectrum.

Methyl groups assignment and figure preparation were done with CCPN Analysis (Vranken et al. 2005). All 14 Ile $\delta_{1}$ and 25 Leu $\delta_{1,2}$ groups were assigned as well as 24 out of 28 Val $\gamma_{1,2}$ (Fig. 3). Due to lack of backbone assignment for V1935 and V1936, partial assignment of V1933, and overlap in spectra, the methyl groups of V1777, V1933, V1935 and V1936 were not assigned.

All obtained backbone and methyl chemical shifts of SARS-CoV-2 Nsp3 CoV-Y have been deposited at the BMRB under accession number 51074.

Our results provide a foundation for future NMR studies of nsp3 CoV-Y domain to identify interaction partners and to understand the molecular mechanism of DMV formation.
Acknowledgements This work is a contribution from the international covid19-nmr consortium (https://covid19-nmr.de)

Funding This work was supported by the US National Science Foundation via Grant RAPID 2030601, and by the US National Institutes of Health Grants R01GM123249 and P41GM111135.

Data availability The values for ${ }^{1} \mathrm{H},{ }^{13} \mathrm{C}$ and ${ }^{15} \mathrm{~N}$ backbone chemical shifts and ${ }^{1} \mathrm{H},{ }^{13} \mathrm{C}$ for Ile $\delta_{1}$, Leu $\delta_{1,2}$ and Val $\gamma_{1,2}$ methyl groups of SARS-CoV-2 Nsp3 CoV-Y have been deposited at the Biological Magnetic Resonance Data Bank (BMRB) (https://www.bmrb.wisc.edu) under Accession Number 51074.

\section{Declarations}

Conflict of interest The authors declare that they have no conflict of interest.

\section{References}

Altincekic N, Korn SM, Qureshi NS et al (2021) Large-scale recombinant production of the SARS-CoV-2 proteome for high-throughput and structural biology applications. Front Mol Biosci 8:1-25. https://doi.org/10.3389/fmolb.2021.653148

Angelini MM, Akhlaghpour M, Neuman BW, Buchmeier MJ (2013) Severe acute respiratory syndrome coronavirus nonstructural proteins 3, 4, and 6 induce double-membrane vesicles. Mbio 4:1-10. https://doi.org/10.1128/mBio.00524-13

Delaglio F, Grzesiek S, Vuister GW et al (1995) NMRPipe: a multidimensional spectral processing system based on UNIX pipes. $\mathbf{J}$ Biomol NMR 6:277-293

Hagemeijer MC, Monastyrska I, Griffith J et al (2014) Membrane rearrangements mediated by coronavirus nonstructural proteins 3 and 4. Virology 458-459:125-135. https://doi.org/10.1016/j. virol.2014.04.027

Imbert I, Snijder EJ, Dimitrova M et al (2008) The SARS-coronavirus PLnc domain of nsp3 as a replication/transcription scaffolding protein. Virus Res 133:136-148. https://doi.org/10.1016/j.virus res.2007.11.017

Keller RLJ (2004) The computer aided resonance assignment tutorial. CANTINA Verlag, Goldau, Switzerland

Lei J, Kusov Y, Hilgenfeld R (2018) Nsp3 of coronaviruses: structures and functions of a large multi-domain protein. Antiviral Res 149:58-74. https://doi.org/10.1016/j.antiviral.2017.11.001

Neuman BW (2016) Bioinformatics and functional analyses of coronavirus nonstructural proteins involved in the formation of replicative organelles. Antiviral Res 135:97-107. https://doi.org/10. 1016/j.antiviral.2016.10.005

Shen Y, Bax A (2015) Protein structural information derived from nmr chemical shift with the neural network program talosn. Methods Mol Biol 1260:17-32. https://doi.org/10.1007/ 978-1-4939-2239-0_2

Shulla A, Randall G (2016) (+) RNA virus replication compartments: a safe home for (most) viral replication. Curr Opin Microbiol 32:82-88. https://doi.org/10.1016/j.mib.2016.05.003

Tugarinov V, Kay LE (2003) Ile, Leu, and Val Methyl assignments of the 723-residue malate synthase $\mathrm{G}$ using a new labeling strategy and novel NMR methods. J Am Chem Soc 125:13868-13878. https://doi.org/10.1021/ja030345s 
Tugarinov V, Kay LE (2004) An isotope labeling strategy for methyl TROSY spectroscopy. J Biomol NMR 28:165-172. https://doi. org/10.1023/B:JNMR.0000013824.93994.1f

Tugarinov V, Kay LE, Ibraghimov I, Orekhov VY (2005) Highresolution four-dimensional $1 \mathrm{H}-13 \mathrm{C}$ NOE spectroscopy using methyl-TROSY, sparse data acquisition, and multidimensional decomposition. J Am Chem Soc 127:2767-2775. https://doi.org/ 10.1021/ja044032o

Vranken WF, Boucher W, Stevens TJ et al (2005) The CCPN data model for NMR spectroscopy: development of a software pipeline. Proteins Struct Funct Genet 59:687-696. https://doi.org/10. 1002/prot.20449

Wolff G, Limpens RWAL, Zevenhoven-Dobbe JC et al (2020) A molecular pore spans the double membrane of the coronavirus replication organelle. Science 369:1395-1398. https://doi.org/10. $1101 / 2020.06 .25 .171686$
Yang D, Kay LE (1999) Improved lineshape and sensitivity in the HNCO-family of triple resonance experiments. J Biomol NMR 14:273-276. https://doi.org/10.1023/A:1008381929212

Ying J, Delaglio F, Torchia DA, Bax A (2017) Sparse multidimensional iterative lineshape-enhanced (SMILE) reconstruction of both nonuniformly sampled and conventional NMR data. J Biomol NMR 68:101-118. https://doi.org/10.1007/s10858-016-0072-7

Zhang O, Kay LE, Olivier JP (1994) Backbone $1 \mathrm{H}$ and $15 \mathrm{~N}$ resonance assignments of the $\mathrm{N}$-terminal SH3 domain of drk in folded and unfolded states using enhanced-sensitivity pulsed field gradient NMR techniques. J Biomol NMR 4:845-858

Publisher's Note Springer Nature remains neutral with regard to jurisdictional claims in published maps and institutional affiliations. 